\title{
Dynamics of generation values and environmental ethics in the information space: case of a metropolis and regional centre
}

\author{
Margarita I. Postnikova ${ }^{1, *}$, Anastasia V. Miklyaeva ${ }^{2}$, Nadezhda V. Sivrikova ${ }^{3}$, and Vlada I. \\ Pishchik $^{4}$ \\ ${ }^{1}$ Northern (Arctic) Federal University named after M.V. Lomonosov, Arkhangelsk, Russia \\ ${ }^{2}$ Herzen State Pedagogical University, St. Petersburg, Russia \\ ${ }^{3}$ South Ural State Humanitarian Pedagogical University, Chelyabinsk, Russia \\ ${ }^{4}$ Don State Technical University, Rostov-on-Don, Russia
}

\begin{abstract}
The article presents the values of generations living in different regions of North-West Russia. The research identified changes in the values of generations over the period of 2009-2018. The first stage was conducted in 2009 , the second one in 2018 . The study involved 769 people (288 men and 481 women) aged 16-83 living in Arkhangelsk and Arkhangelsk region, St. Petersburg and Leningrad region. The theoretical and methodological basis of the study was a sociological approach to generations as well as socio-psychological interpretation of a generation as a large social group. We tested our hypothesis ether there are any differences in generational values and how they changed since 2009 in a Metropolis and Regional Centre. We studied values using the Russian version of Schwartz's Value Survey adapted by V. Karandashev (Karandashev, 2004). Statistical analysis was carried out with the help of Statistica 10.0 software package. We calculated primary statistics and used the criteria analysis applying the Mann-Whitney criterion $(Z)$. The results showed that: 1) values are a good indicator for monitoring the processes of social and individual change resulting from historical, social, and personal events; 2) value orientations of residents of a metropolis demonstrate relatively high stability; 3 ) values of older generations are more stable; 4) younger generations contribute most to the generational dynamics of values.
\end{abstract}

\section{Introduction}

\subsection{Literature review}

In modern society there is a constant growth of interest in the problems of relations between generations. They pay special attention to the generational differences in values, as the theory of generations postulates that each generation has peculiar values and a structure of relations [1], well-defined features of mentality [2]. A generation can be considered as an

\footnotetext{
* Corresoinding author: post-margarita@yandex.ru
} 
element of culture, as a demographic aspect of self-identity [3]. Values are a good indicator for monitoring the processes of social and individual change resulting from historical, social and personal events. Individuals belonging to different social groups significantly differ in value priorities $[4 ; 5]$. These differences reflect their genetic heritage, personal experience, social status and cultural influence. Schwartz's studies allowed to reveal pan-cultural hierarchy of values. The hierarchy meets the requirements of successful societal functioning: preservation of cooperative relations between members of primary groups (primarily families), the need to invest time, physical and the intellectual effort to perform productive work, gratification of self-oriented needs and desires [5].

Studies conducted in different countries have shown that generations significantly differ in values. They point out that the transformation of generations' mentality affected personal values $[3 ; 6]$, family and gender values $[7 ; 8]$, managerial values $[9 ; 10]$, labor/work values [11-15], civic values [16], political and economic values [17], patriotic values [18], cultural values [19]. Researchers have found significant evidence of generational differences in values. They indicate that the new generation, and especially Millennials, tends to be more selfish and to care less about others. This generation has less need for social approval, gives more positive self-esteem, and is less interested in intrinsic goals (self-development, creativity) and more interested in extrinsic ones (money, fame) $[2 ; 3 ; 20 ; 21]$.

However, the studies have a number of limitations. First, most of them use foreign samples: Australia [6; 22], the USA [13], Turkey [3], Africa [12], Central and Eastern Europe $[9 ; 17]$, China $[8 ; 15 ; 23]$. Only a small number of studies focus on the analysis of generational values in the post-Soviet space [20] and in some regions of Russia (Yakutia [7], the Volga region [18], the Central region [11], the Southern Russia [24]). Second, most national studies are based either on a comparison of two age groups (older and younger [25], adult and young [26], students and their parents [11], secondary school students and their parents [17]), or on a same-age comparison of data from different years (2005 and 2012 [16]; 1961, 1970, 1980, 2010 [27]).

Thus, on the one hand, there is evidence that in Russia young people prefer individualistic values, and the adult generation lays weight on collectivistic ones. On the other hand, it remains unknown to what extent these trends are typical for the North-Western Russia. In addition, the question of the dynamics of values in different generations over the past 10 years remains open.

\subsection{Problem Statement}

Scientists widely discuss the dynamics of generational values. In 1990 R. Inglehart and W.E. Baker conducted the World Values Survey. As a result of industrialization, according to the authors, people around the world refused traditional values in favor of secular (rational) [28]. Data from Chinese researchers show that in their country the younger generation has already moved from traditional to modern values. The new generation of Chinese tends to be more secular, more selfish. They are more likely to regard selfdevelopment as the most important thing in life [29]. With regard to Turkey, it was found that in the 2000s the Turks became more individualistic, less distant, more masculine and less subject to uncertainty compared to the Turks of the 1980s [30]. A comparison of the results of studies conducted in 1998 and 2009 confirmed it [3]. The data show that after the collapse of the USSR modernist and individualistic values became prevailing among the younger generation in Kazakhstan. As for the older generation, based on traditional values and a code of conduct, the formation of a new system of values is controversial [20].

Russian researchers also compare the values of different generations. P.Yu. Tazov argues that sociocultural processes of the $60 \mathrm{~s}$ in Russia have set "romanticism" in the value conscious-ness of the youth, which further, in process of disappointment with 
the ideas of building a communist society in the late seventies, gradually began to give way to individualism. Transition to market economy has strengthened individualistic orientation in the values of young people, while the collapse of "collectivist" morality and the lack of cultural and social integrators of society have strengthened personal autonomy. The author identifies the key values typical for different generations of young people in 1960-2010. He believes that the generation of the $60 \mathrm{~s}$ was characterized by the high importance of the "Benefit society" value. For today's youth, the values of individual success and personal effectiveness are more important [27]. V. A. Goldyreva [26], I. Yu. Lyasina et al. [24] obtained similar results. Studies conducted by these authors in the last 10 years have shown that the younger generation of Russians, unlike the older one, focuses on personal success and comfort, prioritizes values of material wealth and personal values over the social ones.

V. S. Magun and M. G. Rudnev conclude that modern Russian society, in comparison with the Soviet one, to a greater extent develops the values of Openness to change and Selfenhancement, as opposed to the values of Conservation, Concern for others and Care for nature. Comparing the data on Russia with the data obtained in the European Union, the authors note that Russian youth is similar to their foreign peers in terms of the value of Conformity-Tradition, and older Russians in terms of the value of Security. Russian youth is ahead of their peers in almost all European countries in the value of Self-enhancement, and older Russians are ahead of peers from 17 countries. According to the researchers, in modern Russia these processes have shifted towards the prevalence of the values of Openness and Self-enhancement and lesser prevalence of the values of Conservation, Concern for others and Care for nature [25]. Generational hierarchy of values was revealed [31].

V. A. Goldyreva talks about the gap between generations, which is manifested in the differences in value priorities at the individual level. According to the author, the adult generation has a higher average in Benevolence value, and the young generation in SelfDirection value [26].

It is also important to note the data obtained by L. E. Petrova. She studied professional values of physicians belonging to different generations and found that the older generation of physicians appreciate altruistic, traditional components in their work: teamwork, respect, prestige, stability [32]. A comparison of work values in China demonstrated similar trends. Moreover, Chinese colleagues concluded that generation had a greater impact on work values than age [23].

In addition to the differences, the authors noted common values for all Russians. They state that values of family and health $[11 ; 24]$ remain very significant in the life of representatives of different generations. At the same time, the family and children are at the top of the list of life goals for both men and women [11].

Russia is a complex state in terms of its extent, national and religious diversity, demography, etc. Currently, demographers record an increase in the urban population due to the ongoing migration from rural areas [33]. The population of metropolises has increased significantly (Moscow, Saint Petersburg) [33]. Thus, the majority of Russia's population is concentrated today in metropolises and cities. Therefore, special attention should be paid to the study and comparison of the values of people living in different regions, urban and rural areas. However, we have not seen studies of the values of residents of metropolises and regional centers. At the same time, some foreign researchers emphasize the need to take this factor into account [3]. Our research makes it possible to fill this gap.

Summarizing the analysis of the studies, we can conclude that in Russia there are differences in individual values among representatives of different birth cohorts: young people prefer values that express interests of the individual, and the adult generation prefer values that express interests of the group. Nonetheless, the following questions remain insufficiently studied: 1) the dynamics of generational values in Russian society; 2) the 
impact of socio-cultural conditions on changes in generational values; 3 ) the differences in generational values.

\subsection{Current study}

This research aims to study the differences in generational values and changes in their structure from 2009 until 2018. Comparison of values in birth cohorts over different periods allows to carry out a cross-sectional analysis of the change in generational values and to exclude the influence of age and career on personal values related to culture. Researchers have so far conducted similar studies in Russia only on a sample of schoolchildren and their parents and only in relation to patriotic values (Tsvetkova, 2014). Our study sought answers to the following research questions: 1) What are the general dynamics of values of the population in the North West Russia over the last decade? 2) What are the differences in the change of values over the last decade in a metropolis (on the example of St. Petersburg) and a regional center (on the example of Arkhangelsk)? 3) What generations contribute most to the dynamics of values? 4) What are the specifics of generational dynamics of values in a metropolis and a regional center?

\section{Materials and Methods}

The study involved 769 people, including 362 people interviewed in 2009 (147 men and 215 women aged 21-83), and 407 people who participated in the study in 2019 (141 men and 266 women aged 21-80). $3.9 \%$ of respondents have incomplete secondary education, $36.4 \%-$ secondary education, $17.8 \%$ - incomplete higher education, $41.4 \%$ - higher education.

Criteria for generational differentiation: age/ age period; historical time period (the birth of a person and the period of his/her identity formation); social role in the family (children, grandchildren, great-grandchildren, parents, grandparents).

On the basis of historical analysis, we have identified epochal periods in the history of Russia, which influenced people's self-consciousness formation and determined the characteristic features of generations. In accordance with the criteria for generational differentiation, among which the age period is the determining one, and taking into account the average life expectancy in Russia, we distinguish five generations in modern Russian society: 1. War, post-war generation; 2. Soviet generation (generation of stagnation); 3 . Transitional generation (generation of radical change); 4. Post-Soviet generation; 5. Generation of the new century (they did not participate in the research, as their values are in the formative stages) [31]. A detailed description of the sample is given in Table 1.

Table 1. Sample characteristics (number of people).

\begin{tabular}{|l|c|c|c|c|}
\hline \multirow{2}{*}{ Generations } & \multicolumn{2}{|c|}{$\mathbf{2 0 0 9}$} & \multicolumn{2}{c|}{$\mathbf{2 0 1 8}$} \\
\cline { 2 - 5 } & $\begin{array}{c}\text { St. } \\
\text { Petersburg }\end{array}$ & Arkhangelsk & $\begin{array}{c}\text { St. } \\
\text { Petersburg }\end{array}$ & Arkhangelsk \\
\hline Post-Soviet generation & 48 & 41 & 61 & 44 \\
\hline Transitional generation & 35 & 37 & 61 & 45 \\
\hline Soviet generation & 63 & 34 & 60 & 41 \\
\hline War, post-war generation & 56 & 42 & 60 & 41 \\
\hline
\end{tabular}

The study was conducted using the Schwartz's Value Survey adapted by V.N. Karandashev [34]. Sh. Schwartz together with Russian researchers justified and developed a new version of the Survey [35]). We chose the older version for this research, as it had been used in our large-scale study of the values of Russians in 2009. In the description of the results given below, we use the average values on the scales of Conformity, Tradition, 
Benevolence, Universalism, Self-direction, Stimulation, Hedonism, Achievement, Power and Security. For ease of comparison, we modified the data to the same dimension based on the number of questions for each scale.

Statistical processing of the research results was carried out with the help of Statistica 10.0 software package. We calculated primary statistics and used the criteria analysis applying the Mann-Whitney criterion (Z).

\section{Results}

The results of the study showed that there is a growing trend in the society towards the transition from traditional to modern values. Figure 1 presents data illustrating changes in the value orientations of the population of the North West Russia over the past decade. Comparative analysis of the results obtained in 2009 and 2018 shows the greatest discrepancy in the average values on the scales of Self-direction and Universalism. This would suggest that the values of these two groups over the last decade are characterized by the most positive dynamics. Researchers note that people around the world are refusing traditional values in favor of secular (rational) [3; 24-29].

Table 2. Dynamics of values in St. Petersburg (SPb) and Arkhangelsk (A) in 2009-2018. Note: * $\mathrm{p} \leq 0.05 ; * *-\mathrm{p} \leq 0.01 ; * * *-\mathrm{p} \leq 0.001$.

\begin{tabular}{|l|c|c|c|c|c|c|}
\hline \multirow{2}{*}{ Values } & \multicolumn{2}{|c|}{$\mathbf{2 0 0 9}$} & \multicolumn{2}{c|}{$\mathbf{2 0 1 8}$} & \multicolumn{2}{c|}{$\mathbf{Z}$} \\
\cline { 2 - 7 } & SPb & A & SPb & A & SPb & A \\
\hline Conformity & 2.14 & 2.10 & 2.17 & 2.34 & - & $3.94^{* * *}$ \\
\hline Tradition & 2.03 & 1.93 & 1.88 & 2.27 & $2.29^{*}$ & $4.29^{* * *}$ \\
\hline Benevolence & 2.48 & 2.63 & 2.65 & 2.68 & $2.31^{*}$ & - \\
\hline Universalism & 2.34 & 2.45 & 2.46 & 2.65 & - & $3.03^{* *}$ \\
\hline Self-Direction & 2.46 & 2.29 & 2.59 & 2.59 & - & $3.96^{* * *}$ \\
\hline Stimulation & 1.83 & 1.69 & 1.98 & 1.98 & - & $3.21^{* * *}$ \\
\hline Hedonism & 1.67 & 1.45 & 2.04 & 2.06 & $4.65^{* * *}$ & $6.17^{* * *}$ \\
\hline Achievement & 2.01 & 2.12 & 2.20 & 2.24 & $2.85^{* *}$ & - \\
\hline Power & 2.02 & 1.64 & 1.85 & 1.85 & $2.37^{*}$ & $2.46^{* *}$ \\
\hline Security & 2.29 & 2.61 & 2.46 & 2.63 & $2.65^{* *}$ & - \\
\hline
\end{tabular}

3.00

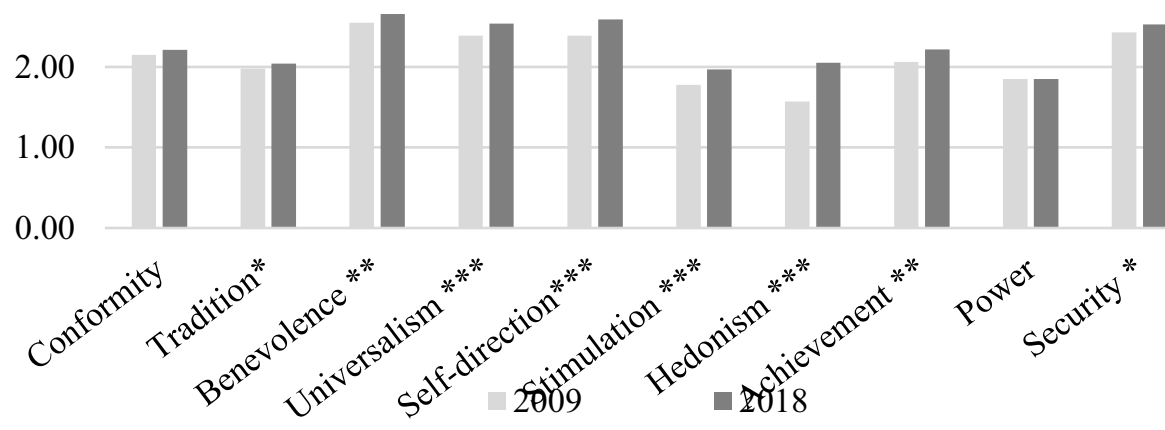

Fig. 1. Dynamics of values of the population in the North-West Russia in 2009-2018. Note: * $\mathrm{p} \leq 0.05 ; * *-\mathrm{p} \leq 0.01 ; * * *-\mathrm{p} \leq 0.001$.

The results presented in Table 2 show that the above-mentioned changes in the value orientations of the population of North-West Russia are typical for both St. Petersburg and Arkhangelsk, although the intensity of these changes varies. The results obtained in samples of residents of Arkhangelsk make the biggest changes in dynamics of values (Figure 1). 
Table 3. Generational dynamics of value orientations (difference between 2009 and 2018). Note: PS - Post-Soviet generation, T - Transitional generation; S - Soviet generation: PW - Post-War generation; $*-p \leq 0.05 ; * *-p \leq 0.01 ; * * *-p \leq 0.001$.

\begin{tabular}{|c|c|c|c|c|c|c|c|c|}
\hline \multirow{2}{*}{ Values } & \multicolumn{4}{|c|}{2009} & \multicolumn{4}{|c|}{$\mathbf{p}<$} \\
\hline & PS & $\mathbf{T}$ & $\mathbf{S}$ & PW & PS & $\mathbf{T}$ & $\mathbf{S}$ & PW \\
\hline \multicolumn{9}{|c|}{ For the sample as a whole } \\
\hline Conformity & -0.32 & -0.01 & -0.11 & -0.32 & - & 0.05 & - & - \\
\hline Tradition & -0.29 & -0.07 & -0.06 & -0.29 & - & 0.05 & - & - \\
\hline Benevolence & -0.33 & 0.01 & -0.09 & -0.33 & - & 0.05 & - & - \\
\hline Universalism & -0.16 & 0.04 & -0.14 & -0.16 & 0.01 & - & - & - \\
\hline Self-Direction & -0.38 & 0.03 & -0.18 & -0.38 & 0.01 & 0.05 & - & - \\
\hline Stimulation & -0.42 & 0.01 & -0.26 & -0.42 & - & 0.05 & - & - \\
\hline Hedonism & -0.61 & -0.31 & -0.47 & -0.61 & 0.01 & 0.01 & 0.01 & 0.01 \\
\hline Achievement & -0.18 & 0.05 & -0.37 & -0.18 & - & - & - & 0.01 \\
\hline Power & -0.37 & 0.13 & 0.09 & -0.37 & - & 0.05 & - & - \\
\hline Security & -0.17 & -0.14 & -0.08 & -0.17 & - & - & - & - \\
\hline \multicolumn{9}{|c|}{ In the sample of Arkhangelsk } \\
\hline Conformity & -0.25 & -0.28 & -0.16 & -0.25 & $2.26^{*}$ & $2.31 *$ & $2.04 *$ & \\
\hline Tradition & -0.45 & -0.44 & -0.14 & -0.45 & $2.03^{*}$ & $2.70 * *$ & $2.71 * *$ & \\
\hline Benevolence & -0.06 & 0.14 & -0.16 & -0.06 & - & - & - & \\
\hline Universalism & -0.05 & -0.09 & -0.27 & -0.05 & $2.52 * *$ & - & - & $2.29 *$ \\
\hline Self-Direction & -0.49 & -0.19 & -0.12 & -0.49 & $2.30 *$ & $3.15^{* *}$ & - & \\
\hline Stimulation & -0.29 & -0.16 & -0.3 & -0.29 & $2.23^{*}$ & - & - & \\
\hline Hedonism & -0.49 & -0.73 & -0.61 & -0.49 & $3.16^{* *}$ & $2.66 * *$ & $3.19 * * *$ & $3.38 * * *$ \\
\hline Achievement & -0.01 & -0.08 & -0.16 & -0.01 & - & - & - & \\
\hline Power & -0.35 & -0.17 & -0.02 & -0.35 & - & $1.96^{*}$ & - & \\
\hline Security & -0.04 & -0.08 & 0.04 & -0.04 & - & - & - & \\
\hline \multicolumn{9}{|c|}{ In the sample of Saint Petersburg } \\
\hline Conformity & -0.39 & 0.17 & -0.1 & -0.39 & $2.27 *$ & $2.98 * *$ & - & - \\
\hline Tradition & -0.19 & 0.18 & 0 & -0.19 & $3.19^{* *}$ & - & - & - \\
\hline Benevolence & -0.58 & -0.05 & -0.06 & -0.58 & - & $4.03 * * *$ & - & - \\
\hline Universalism & -0.26 & 0.14 & -0.06 & -0.26 & $2.17^{*}$ & - & - & - \\
\hline Self-Direction & -0.26 & 0.17 & -0.19 & -0.26 & $1.97 *$ & - & - & - \\
\hline Stimulation & -0.53 & 0.12 & -0.21 & -0.53 & - & $3.17 * *$ & - & - \\
\hline Hedonism & -0.7 & -0.08 & -0.36 & -0.7 & $2.53 * *$ & $3.61 * * *$ & - & $2.26^{*}$ \\
\hline Achievement & -0.34 & 0.15 & -0.5 & -0.34 & - & $1.97 *$ & - & $4.69 * * *$ \\
\hline Power & -0.34 & 0.29 & 0.18 & -0.34 & $2.85^{* *}$ & $2.04 *$ & - & - \\
\hline Security & -0.31 & -0.14 & -0.2 & -0.31 & - & - & - & $2.39 *$ \\
\hline
\end{tabular}

The data presented in table 3 show that the values of the transitional generation are the most dynamic. The values of the older generations have not changed significantly over the past decade, with the exception of Hedonism value, the importance of which has significantly grown in all generations. At the same time, all generations without exception rank such values as Benevolence, Universalism, Self-direction and Security in the first priority.

Generational dynamics of values typical for the respondents from Saint-Petersburg and Arkhangelsk are largely similar. However, more expressed dynamics of values are observed in residents of Arkhangelsk. They were characterized by more significant changes of value orientations not only in the post-Soviet and transitional generations, but also in older generations. 


\section{Discussion}

Research question 1: What are the general dynamics of values of the population in the North West Russia over the last decade? The results of our study showed that the leading value orientations for all generations are Benevolence, Universalism, Self-direction and Security. Their positions in the value ranking have not changed over the past 10 years, but their importance has increased significantly. The results of other studies conducted in recent years show that Russians, regardless of age, prioritize Security and Self-direction [36].

In general, according to the data obtained, the greatest changes over the last decade have occurred in the values of Self-enhancement and Openness to change. P. Tazov noted similar findings. He points out that the values of pre-perestroika youth are largely associated with traditions and the values of post-perestroika youth with archaization [27]. Comparing our data with the results of similar studies conducted on foreign samples, we can observe the following trends in the Turkish society: in generation X, the changes have affected both the importance of individual values and their hierarchy; in the generation of baby boomers, the changes in the importance of individual values have not led to changes in the hierarchy of values [3]. Moreover, the values of Conservation and Concern for others became dominant in the hierarchy of values for both generations by 2009 [3]. It should also be noted that in our country the structure of patriotic values of residents of Togliatti underwent significant changes in the period from 2005 to 2012 [18]. The dynamics of values might significantly depend on socio-cultural factors and on what values have become the subject of researchers' attention.

It is necessary to note the visible increase of such values as Universalism, Self-direction, Hedonism, and to a lesser extent, of the value of Achievement. It is important to mention that the value of Hedonism demonstrates the most expressed dynamics in all generations. The values characterized by the desire to preserve stability (Conformity, Tradition) have undergone the least changes. Also, there were no changes in the significance of the value of Power.

Research question 2: What are the differences in the change of values over the last decade in a metropolis (on the example of St. Petersburg) and a regional center (on the example of Arkhangelsk)? Comparative analysis shows that the value orientations of residents of St. Petersburg demonstrate relatively higher stability. On the contrary, among the residents of Arkhangelsk, there has been a more intensive increase in the importance of the values that are at the top of the value ranking of the respondents, especially the values of Selfenhancement. Attention is drawn to the multidirectional changes in the value of Tradition, the importance of which has decreased over the past decade for the residents of St. Petersburg and grown for those of Arkhangelsk. This could be explained by the fact that a large number of people always move to the metropolis in search of job opportunities and higher earnings [33]. Therefore, the preservation of traditions and common cultural field becomes difficult.

Research question 3: What generations contribute most to the dynamics of values? On the basis of the results obtained, we can argue that the values of the transitional generation are the most dynamic. The values of the older generations have not significantly changed over the past decade, with the exception of Hedonism value, the importance of which has grown significantly in all generations. At the same time, all generations without exception rank such values as Benevolence, Universalism, Self-direction and Security in the first priority. The results indicate that these values tend to be strengthened in modern social situation, especially in regard to Arkhangelsk. This is probably due to a more flexible life position, which was formed from the need to adapt to global social changes that came on the sensitive period of personal development as a subject of social relations.

Research question 4: What are the specifics of generational dynamics of values in a metropolis and a regional center? The generational dynamics of values described above, which are typical for respondents from St. Petersburg and Arkhangelsk, are largely similar. 
In all the subgroups identified in our study Benevolence, Universalism, Self-direction and Security hold top positions in the ranking of values, although for older generations the value of Self-direction is relatively less important in comparison with the value of Security. The values of older generations are more stable than the values of the transitional and post-Soviet generations. It is more evident in the sample of St. Petersburg residents.

Younger generations, mainly the representatives of the transitional generation, contribute most to the generational dynamics of values. Their values undergo significant changes towards the Self-enhancement and life change. This is in line with the general logic of intergenerational changes in value orientations described above. In this context, the results obtained in the samples of the residents of Arkhangelsk and St. Petersburg representing the younger generation are particularly important. If in Arkhangelsk sample there is an increasing orientation to values of stability (Tradition, Conformity), in St. Petersburg sample we found an opposite tendency. As a matter of interest, cultural value shifts towards autonomy and assertiveness emerged in urban families in developing collectivistic societies like India, China, Japan, and Turkey are associated with the socio-demographic changes in the global context [37-39]. These changes correlate with levels of education and urbanization across the country, especially for younger generations, indicating a shift in generational values [38].

Thus, we can argue that the trends are rather similar for the post-war, Soviet and transitional generations. We observed differences only in the dynamics of value orientations of the post-Soviet generation. It can be explained by the fact that before the 2000's, the most important was the situation in the country, which was perceived as being equal for all. But now the values of regional identity tend to dominate, and young people are sensitive to this.

\section{Conclusions}

In the North-Western regions of Russia value orientations, which are ranked high in the ranking of values, remain stable over the past decade. Benevolence, Universalism, Selfdirection and Security hold top positions in the ranking of values in all generations. The general trend is towards a consistent increase in the values of Self-enhancement and Openness to change, with the value of Hedonism demonstrating the most expressed dynamics in all generations. The value orientations of the residents of St. Petersburg are relatively more stable. Among the residents of Arkhangelsk there is a more intensive increase in the importance of Self-enhancement, as well as the increase in values that support life stability. The values of the transitional generation showed the most expressed dynamics over the past decade. The values of the older generation are more stable. At the same time, for the postwar, Soviet and transitional generations, the trends of changes in value orientations that have occurred over the past decade are generally similar. We observed differences only in the dynamics of value orientations of the post-Soviet generation, which are region-specific.

\section{Acknowledgements}

This work was supported by the Russian Foundation for Humanities (project № 18-013-00910 A).

\section{References}

1. Sivrikova, N. V. Problems of research on generations in psychology. Cultural-historical psychology, 11(2), 100-107 (2015). DOI: 10.17759/chp.2015110210 (In Russ.)

2. Pishchik, V. I. Transformation of value and semantic components of mentality of population of the South of Russia. Voprosy psikhologii, 3, 81-91 (2008) (in Russ.) 
3. Marcus, J., Ceylan, S., Ergin, C. Not So "Traditional" anymore? Generational shifts on Schwartz values in Turkey. Journal of Cross-Cultural Psychology, 48(1), 58-74, (2017). DOI: $10.1177 / 0022022116673909$

4. Rokeach, M. The nature of human values. New York, Free Press (1973).

5. Schwartz, S., Bardi, A. Value hierarchies across cultures: Taking a similarities perspective. Journal of Cross-Cultural Psychology, 32, 268-290 (2001) https://doi.org/10.1177/0022022101032003002 (In Russ.)

6. Heritage, B., Breen, L. J., Roberts, L. D. In-groups, Out-groups, and their contrasting perceptions of values among generational cohorts of Australians. Australian Psychologist, 51(3), 246-255 (2016). DOI: 10.1111/ap.12114

7. Barashkova, A., Sukneva, S. Marital decline in the Asian North of Russia and generational transition of family values. Asian Social Science, 11(21), 203-212 (2015). DOI: 10.5539/ass.v11n21p203 (In Russ.)

8. Hu, Y., Scott, J. Family and Gender Values in China: Generational, Geographic, and Gender Differences. Journal of Family Issues, 37(9), 1267-1293 (2016). DOI: $10.1177 / 0192513 X 14528710$

9. Van Hoorn, A. Generational Shifts in Managerial Values and the Coming of a Unified Business Culture: A Cross-National Analysis Using European Social Survey Data. Journal of Business Ethics, 155(2), 547-566 (2019). DOI: 10.1007/s10551-017-3488-4

10. Weber, J. Identifying and assessing managerial value orientations: a cross-generational replication study of key organizational Decision-Makers' values. Journal of Business Ethics, 132(3), 493-504 (2015). DOI: 10.1007/s10551-014-2364-8

11. Nemova, O. A., Retivina, V. V., Kutepova, L. I., Vinnikova, I. S., Kuznetsova, E. A. Sociocultural mechanisms of intergenerational values and mindset translation in modern family development and generational change. International Journal of Environmental and Science Education, 11(13), 6226-6237 (2016).

12. Jonck, P., Van der Walt, F., Sobayeni, N. C. A generational perspective on work values in a South African sample. South African Journal of Industrial Psychology, 43, a1393 (2016). DOI: 10.4102/sajip.v43i1.1393

13. Kalleberg, A. L., Marsden, P. V. Work values in the United States: age, period, and generational differences. The ANNALS of the American Academy of Political and Social Science, 682(1), 43-59 (2019). DOI: 10.1177/0002716218822291

14. To, S. M., Tam, H. L. Generational differences in work values, perceived job rewards, and job satisfaction of Chinese female migrant workers: implications for social policy and social services. Social Indicators Research, 118(3), 1315-1332 (2014). DOI: 10.1007/s11205-013-0470-0

15. Jian, C., Rong, L. Generational differences in work values in China. Social Behavior and Personality: an international journal, 43(4), 567-578 (2015). DOI: 10.2224/sbp.2015.43.4.567

16. Janmaat, J. G. Values in times of austerity: a cross-national and cross-generational analysis. Citizenship Teaching \& Learning, 11(3), 267-287 (2016). DOI: 10.1386/ctl.11.3.267_1

17. Turkina, E., Surzhko, Harned, L. Generational differences in values in Central and Eastern Europe: the effects of politico-economic transition. Journal of Common Market Studies, 52(6), 1374-1397 (2014). DOI: 10.1111/jcms.12155

18. Tsvetkova, I. V. Generational variations in patriotic values dynamics (city of Togliatti's case). Sociological Studies, 3, 45-51 (2014). (In Russ.) 
19. Lebedeva, N. Cultural values, economic settings, and aptitudes towards innovations in Russia. Psychology. Journal of Higher School of Economics, 5(2), 68-88 (2008). (In Russ.)

20. Abdikakimov, M. Changing values in the context of generational approach in Kazakhstan. Asian Social Science, 11(4), 181-191 (2015). DOI: 10.5539/ass.v11n14p181

21. Tang, F. Psychological features of interaction between generations in China on the example of the family relations. World of science, culture, education, 5(54), 249-251 (2015).

22. Gardiner, S., King, C., Grace, D. Travel Decision Making: An Empirical Examination of Generational Values, Attitudes, and Intentions. Journal of Travel Research, 52(3), 310-324 (2013). DOI: 10.1177/0047287512467699

23. Chan, R. K., Wang, L. R. Generational conflict and provisions for the elderly in Hong Kong: The relevance of position based interest and values. Asian Social Work and Policy Review, 13(1), 25-35 (2019). DOI: 10.1111/aswp.12153

24. Lyasina, I. Yu., Sokolov, R. V., Khvan, N. S. Practice of application of the theory of generations in research of distinctions in values of Russians (analysis of results of sociological research in Volzhsk of the Volgograd region). Primo Aspectu. 18-16 (143), 105-107 (2016). (In Russ.)

25. Magun, V. S., Rudnev, M. G. Basic values of two generations of Russians and the dynamics of their social determination. Social studies and modernity, 3, 87-97 (2010). (In Russ.)

26. Goldyreva, V. A. Interrelation of values and ideas of business ethics at different generations of Russians. Psychological science and education, 1, 86-95 (2013). (In Russ.)

27. Tazov, P. Yu. Dynamics of values of the Russian youth of 1960-2010 in the sociocultural analysis. Modern problems of science and education, 1-1, http://scienceeducation.ru/ru/article/view?id=17928 (last accessed 11/04/2020) (2015). (In Russ.)

28. Inglehart, R., Baker, W. E. Modernization, cultural change, and the persistence of traditional values. American sociological review, 65 (1), 19-51 (2000). DOI: $10.2307 / 2657288$

29. Breitsohl, H., Ruhle, S. Differences in work-related attitudes between Millennials and Generation X: Evidence from Germany. In: Managing the new workforce: international perspectives on the millennial generation, pp. 107-129. Cheltenham, Edward Elgar (2013).

30. Taras, V., Steel, P., Kirkman, B. L. Improving national cultural indices using a longitudinal meta-analysis of Hofstede's dimensions. Journal of World Business, 47, 329-341 (2012). DOI: 10.1016/j.jwb.2011.05.001

31. Postnikova, M. Psychology of Intergenerational Relations in modern Russia]. Thesis for the degree of doctor of psychological Sciences. Saint Petersburg, Herzen State Pedagogical University of Russia (2010). (In Russ.)

32. Petrova, L. E. Generational differences in social and professional groups of physicians as a factor of quality of medical care. Social aspects of health of the population]. 3, http://vestnik.mednet.ru/content/view/570/30/lang,ru_ru.cp1251/(last accessed 15.07.2020) (2014). (In Russ.)

33. Regions of Russia. Socio-economic indicators. Statistical comp. (2014). https://gks.ru/bgd/regl/B14_14p/Main.htm (last accessed 04/03/2021). (In Russ.) 
34. Karandashev, V. Schwartz's method for the study of personal values. Saint Petersburg, Rech' (2004). (in Russ.)

35. Schwartz, S., Butenko, T., Sedova, D., Lipatova, A. A. Refined Theory of Basic Individual Values: application in Russia. Psychology. Journal of the Higher school of Economics, 9(1), 43-70 (2012) https://psy-journal.hse.ru/en/2012-9-2/53395751.html

36. Fedotova, V. A. Individual Values as Predictors of positive or negative Attitudes towards Innovation among Representatives of Various Generations of Russian People. Psychology. Journal of the Higher School of Economics, 14(4), 717-734 (2017). DOI: 10.17323/1813-8918-2017-4-717-734. (In Russ.)

37. Mayer, B., Trommsdorff, G., Kagitcibasi, C., Mishra, R. C. Family models of independence/interdependence and their intergenerational similarity in Germany, Turkey, and India. Family Science., 3, 64-74 (2012). DOI: $10.1080 / 19424620.2011 .671503$

38. Okur, Z. E., Corapci, F. Turkish children's expression of negative emotions: intracultural variations related to socio-economic status. Infant and Child Development, (2015), 25, 440-458 (2015). DOI: 10.1002/icd.1945O’Neal

39. Corapci, F., Benveniste, H., Bilge, S. Does Mothers' Self-Construal Contribute to Parenting Beyond Socioeconomic Status and Maternal Efficacy? An Exploratory Study of Turkish Mothers. Frontiers in Psychology, 9, 1245 (2018). DOI: 10.3389/fpsyg.2018.01245 